\title{
Utility of Neurostimulator-Guided Peripheral Nerve Blocks for Limb Surgery in Patients with Leprosy in a Developing Country
}

\author{
Mamadou Mour traore ${ }^{*}$, Pape Alassane leye ${ }^{1}$, Charles Valérie Alain Kinkpe ${ }^{2}$, Mamadou Diawo bah ${ }^{1}$, Mohamed \\ daffe $^{2}$, Ibrahima gaye ${ }^{1}$ and Elisabeth diouf ${ }^{3}$ \\ ${ }^{1}$ Consultant Anesthesiologist, Cheikh Anta DIOP University, Africa
}

${ }^{2}$ Consultant Orthopedic surgeon, Cheikh Anta DIOP University, Africa

${ }^{3}$ Professor of Anesthesia and Intensive Care Medicine, Cheikh Anta DIOP University, Africa

Submission: August 01, 2017; Published: December 12, 2017

*Corresponding author: Mamadou Mour traore, Consultant Anesthesiologist, Cheikh Anta DIOP university/ Dakar, Senegal, Africa, Tel: +221775504534; Email: mamadoumour@yahoo.fr

\begin{abstract}
Introduction: Leprosy is a disease still present in many countries in Africa, Asia and Latin America mainly in disadvantaged areas where medical facilities are almost non existent [1]. Leprosy is a chronic infectious disease which causes peripheral neuropathy with severe deformities of the extremities as a result.

Objective: We describe the utility of peripheral nerve blocks and nerve stimulator (NS) guided peripheral nerve blocks (PNB) in patients affected by leprosy undergoing surgery.

Methods: We reviewed our institutional use of regional anesthesia in leprous patients between 2011 and 2015. Patients received baseline clinical neurological evaluation before and after PNB. All PNB's were performed with NS-guidance using either Ropivacaine $0.75 \%$ or Bupivacaine $0.5 \%$ as local anesthetics.

Results: Seventy-three patients received a total of 102 PNB's, with a mean age of 28 years [14-80] and a sex ratio of 0.25 (M:F). Forty-four axillary blocks were performed for ulnar (58.09\%), median (40.9\%) and cubital-median (28.5\%) neurolysis. 29 combined sciatic and femoral nerve blocks were performed for posterior tibial neurolysis $(70 \%)$ and leg amputations (30\%).Median current intensity to elicit electro motor response was $0.4 \mathrm{~mA}$. The average block on set time was 20 minutes with a $94 \%$ success-rate and average duration of sensory block was 18 hours. After 6 months, $84.5 \%$ of all patients were re assessed without evidence of neurologic deficit.
\end{abstract}

Conclusion: Leprosy continues to be rampant in developing countries. Patients whose peripheral nerves are affected often require limb surgery. Our data suggests that the practice of NS guided PNB successfully provides anesthesia and analgesia during these procedure.

Keywords: Peripheral Nerve Block; Peripheral Nerve Stimulation; Leprosy

Abbreviations: NS: Nerve Stimulator; PNB: Peripheral Nerve Block; PSIS: Posterior Superior Iliac Spine; SD: Standard Deviation; SFAR: Societe Francaise Anesthesie Réanimation

\section{Introduction}

Leprosy is an infectious, transmissible disease caused by Mycobacterium leprae or Hansen's bacillus (1873), mainly affecting the skin, the mucous membranes, peripheral nervous system, the eyes, and appearing under different clinical forms, depending on the cellular immunity of the infected subject. There has been a considerable decline of leprosy disease over the past two decades, as a result of the intensification of leprosy control activities by WHO. However, leprosy remains a globally important disease with 2,30,000 new cases per year [1]. In Africa, the number of new cases detected has decreased from 34,480 cases in 2006 to 18597 cases in 2014 [2]. In the same year in Senegal, a country also affected by this pandemic, the number of new cases is 230. Despite the multidrug therapy, the incidence of disabling neurological disorders may persist or occur several years after cessation of treatment $[3,4]$.

The prognosis of the disease is essentially functional by the various peripheral nerve damages caused. These functional impairments can sometimes require palliative or radical surgery at the extremities of the limb. The techniques of regional anesthesia by neurostimulation proposed to the patients ungoing 
to limb surgery remain weakly developed in the literature. Our work aims to describe the utility of peripheral nerve blocks by neurostimulation in the leprous patient in a low-resource context.

\section{Patients and Methods}

\section{Patient and Data Collection}

The study included all leprous patients who benefited from a peripheral nerve block through neurostimulation for limb surgery. The data were collected retrospectively on the anesthesia record sheets and the follow-up medical records from July 2011 to August 2015 at the Centre Hospilatier de l'Ordre de Malte in Dakar. Incomplete files were excluded from the study. For each patient we were interested in the classification of leprosy according to Ridley and Jopling, the corticosteroid therapy, the ASA class, the initial clinical neurological assessment and after peripheral nerve block in the 6 months, the type of surgery, neurostimulation parameters and the success of the peripheral block, and an improvement or not of the pain scores within 48 hours in case of hyperalgic neuritis.

\section{Neurological Evaluation and Neurostimulation}

All patients underwent a preoperative assessment recorded on the anesthesia form. Nerve damages were noted and mapped on a neuro-clinical assessment form (Figure 1). The clinical examination of the nerves depended on one hand on their palpation and on the other hand on the quantitative evaluation of the 3 elemental sensitivities in their skin territory on hand and foot. Tactile sensitivity was studied by Von Frey hair method ( 0.5 and $0.2 \mathrm{~g}$ filament), modified by Pearson \& weddell. The sensitivity of the pain was appreciated by the puncture of a sterile pin at the same points. Thermal sensitivity was studied by dropping a drop of ether into the skin or by applying ice. Patients with complete paralysis did not benefit from neurostimulation. The peripheral blocks were made in the operating room by a senior anesthesiologist. Standard monitoring included an electrocardioscope, non-invasive arterial pressure and a pulse oximeter. The criteria of neurostimulation were those edicted by the recommendations for clinical practice of SFAR (French Society of Anesthesia and Intensive care medecine) in 2003 [5].

We deliberately increased the intensity at $3 \mathrm{~mA}$ in order to reduce the risk of intraneural injection at the first puncture. The neurostimulation was performed by two devices, Plexygon $®$ type (Vygon) or HNS-12® (BBraun). The short-bevelled insulaled needles were isolated of variable sizes depending on the patient's corpulence: $50 \mathrm{~mm}$ to $100 \mathrm{~mm}$ Stimuplex® type A or D or Locoplex ®. The local anesthetic solutions used were either ropivacaine $0.75 \%$ or bupivacaine $0.5 \%$. The procedures depended of the type of block as followed.

\section{Axillary Brachial Plexus Blockade}

It is performed at the level of the insertion of pectoralis major muscle into humerus. The patients were positioned supine with arm abducted to 90 degrees and the elbow flexed. After skin preparation with antiseptic solution, a 22-gauge,
$50 \mathrm{~mm}$ short-bevelled insulaled needle was connected to a nerve stimulator with an initial setting of $3 \mathrm{~mA}$. Local anesthetic was used with the following increments order (median nerve $6 \mathrm{ml}$, musculocutaneous nerve $4 \mathrm{ml}$ and radial nerve at the end $15 \mathrm{ml}$ ). Triple injection technique was used as superior axillary artery to locate median and musculocutaneous nerves and inferior to locate radial nerve and the ulnar nerve was not located separately. The objective was to inject local anesthetic when an appropriate motor response occured between $0,3-0,5 \mathrm{~mA}$ at 0,1 millisecond pulse, as recommended [6].

\section{Femoral Nerve Blockade}

It was performed at the mid point of the inguinal ligament $1 \mathrm{~cm}$ distal and $1-1.5 \mathrm{~cm}$ lateral to the femoral artery. The patient were in supine position with the leg extended. The classical endpoint was the quadriceps contraction. A 22-gauge, $100 \mathrm{~mm}$ short-bevelled insulated needle was used as the same needle performing sciatic nerve blockade. Local anesthetic was Ropivacaine $0,75 \%$ or Bupivacaine 0,5\%.

\section{Sciatic Nerve Blockade}

By parasacral technique, patients were placed in the lateral decubitus position. Landmarks were posterior superior iliac spine (PSIS) and the ischial tuberosity. A line was drawn connecting these two points and the insert point was at $6 \mathrm{~cm}$ caudal to PSIS. The insert needle was $100 \mathrm{~mm}$. If bone contacted the needle caudally until it advances through the sciatic foramen. All the sensory blocks were tested after removal of the needle at $10 \mathrm{~min}$, $15 \mathrm{~min}$ and $30 \mathrm{~min}$ with ice and the motor block by the absence of voluntary mobility. Failure was notified in the absence of a sensory block $30 \mathrm{~min}$ after the block was made.

\section{Analyses statistiques}

Statistical analysis was conducted using EPI infos version 7. Data are expressed as mean (SD), or median and percentage.

\section{Results}

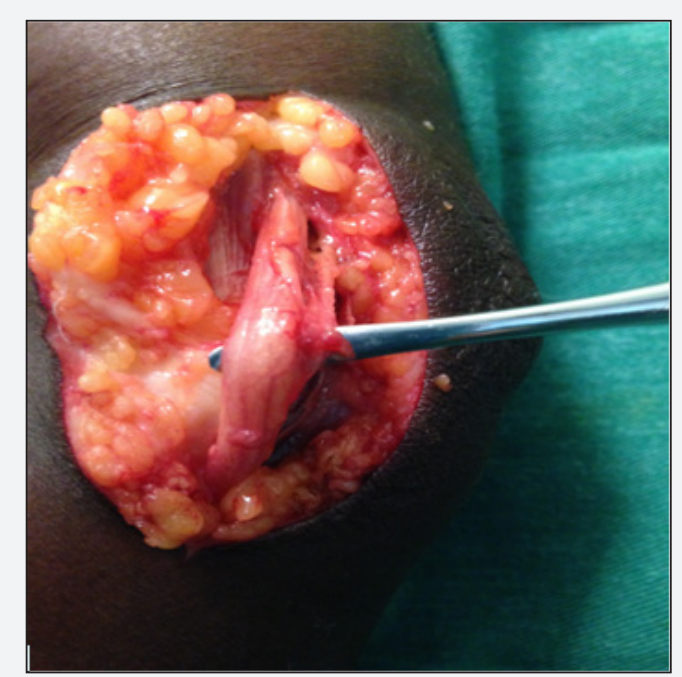

Figure 1: Hypertrophicle prousneuritis of the ulnar nerve. 


\section{Journal of Anesthesia \& Intensive Care Medicine}

Over the period of the study, 73 patients received a total of 102 peripheral nerve blocks. The main exclusion criteria was the lack of data in 14 patients. Medical and demographic caracteritics of patients are reported in Table 1. Preoperative neurologic evaluations with calibrated filamentwere complete in all patients. Surgical indications at upper limb were mainly ulnar neunolysis at $58,02 \%$ (Table $1 \&$ Figure 1) and at the lower limb leg amputation $30 \%$ and tibial neurolysis $70 \%$ (Figure 2)

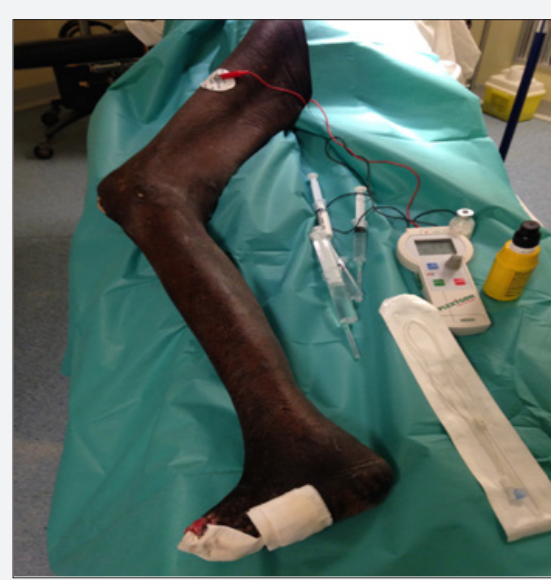

Figure 2: Leprous foot ulcer before amputation.

Table 1: Characteristics of Patients and Surgery.

\begin{tabular}{|c|c|}
\hline Characteristics & Population $=73$ \\
\hline Age $(y)$ & $28(14-80)$ \\
\hline Sex-Ratio (M/F) & 0,25 \\
\hline Weight (kg) & $47(35-82)$ \\
\hline \multicolumn{2}{|c|}{ Type of Leprosis (n) } \\
\hline Polar Tuberculoid & 3 \\
\hline Polar Lepromatous & 9 \\
\hline Bordeline (BT, BB, BL) & $20,27,8$ \\
\hline Non Classification & 6 \\
\hline Duration of Leprosis & $3(1-11)$ \\
\hline \multicolumn{2}{|c|}{ Conclusion of Clinical Evaluation (\%) } \\
\hline Sensitive and Motor Total Deficit & 0 \\
\hline Sensitive and Motor Partial & 92 \\
\hline \multicolumn{2}{|c|}{ Surgical Indications } \\
\hline \multicolumn{2}{|c|}{ Upper Limb } \\
\hline Ulnarneurolysis & 30 \\
\hline Medio-ulnarneurolysis & 9 \\
\hline Medianneurolysis & 5 \\
\hline \multicolumn{2}{|c|}{ Lower Limb } \\
\hline Posterior Tibial Neurolysis & 17 \\
\hline Amputation for Foot Ulcer & 12 \\
\hline Steroidregimen (\%) & 80 \\
\hline
\end{tabular}

Data are presented as mean (SD), median (10th-90th centile) or percentage and $n$ as number

$\mathrm{BT}, \mathrm{BB}, \mathrm{BL}$ indicate respectively Bordeline Tuberculoid, Bordeline Bordeline, Bordeline Lepromatous
The Table 2 shows each nerve block parameters. The nerve stimulation parameters are reported in Table 3. The success rate in all blocks was 92,5\%.The functional gain was increased in $73 \%$ reviewed patients and at the same time no neurologic complications was reported by all the patients. All surgical procedures were performed under tourniquet.

Table 2: Each nerve block characteristics.

\begin{tabular}{|c|c|c|c|c|}
\hline & $\begin{array}{c}\text { Threshold } \\
\text { (mA) }\end{array}$ & $\begin{array}{c}\text { Performance } \\
\text { Duration } \\
(\mathbf{m i n})\end{array}$ & $\begin{array}{c}\text { Onset } \\
\text { Time } \\
\text { (min) }\end{array}$ & $\begin{array}{c}\text { Duration } \\
\text { (min) }\end{array}$ \\
\hline Median Nerve & 0,46 & 2 & 10 & 18 \\
\hline Radial Nerve & 0,6 & 2 & 11 & 18 \\
\hline $\begin{array}{c}\text { Musculocutaneous } \\
\text { Nerve }\end{array}$ & 0,42 & 1,5 & 8 & 17 \\
\hline $\begin{array}{c}\text { Ulnar Nerve } \\
\text { Femoral Nerve }\end{array}$ & 0,40 & 4 & 15 & 16 \\
\hline Tibial Nerve & 0,42 & 6 & 25 & 18 \\
\hline $\begin{array}{c}\text { Common peroneal } \\
\text { Nerve }\end{array}$ & - & - & 20 & 19 \\
\hline
\end{tabular}

Table 3: All block characteristics and outcomes.

\begin{tabular}{|c|c|}
\hline Characteristic & Value \\
\hline Type of Block & (n) \\
\hline Axillary Block & 44 \\
\hline Femoral Block & 29 \\
\hline Sciatic Block & 29 \\
\hline Current Output (mA) & 3 \\
\hline Thresholds (mA) & $0,46(0,30-0,70)$ \\
\hline Onset Time (min) & $20(12-35)$ \\
\hline Sensitive Block Duration (min) & $16(14-26)$ \\
\hline VAS/48h (mm) & $25(0-35)$ \\
\hline Success Rate (\%) & 98 \\
\hline Complications (n) & 6 \\
\hline
\end{tabular}

Values are reported as number of subjects, proportion (percentage), mean (SD)

VAS: Indicates Visual Analog Scale.

\section{Discussions}

Taking into account the data of the literature which was not very productive or even absent on neurostimulated peripheral blocks on the leprous, we conducted this retrospective study in order to describe the interest of these blocks for limb surgery in a context of low resources. This study demonstrates on one hand the feasibility of neurostimulation despite leprous neuropathy, and on the other hand its undeniable advantages compared to 
the techniques such as epidural or general anesthesia that were proposed. Some authors have reported the realization of brachial plexus block using blind techniques without neurostimulator [6,7]. Indeed in 1981, Pfagraft in a letter to the editor, reported the realization of brachial plexus blocks on the leprous patient [6]. Similarly, Debray and al, in the surgical treatmentofleprosyneuritis, used axillary block techniques without neurostimulation and the epidural, facing precarious sanitary conditions [7]. Consequently, our study shows a real interest in the use of neurostimulation on this type of patient who will benefit from limb surgery. Unlike the epidural for tibial or fibular neurolysis, the sciatic nerve block present more interest in terms of postoperative analgesic gain and incidence of postoperative nausea and vomiting.

For surgery of nerve decompressions, these authors have reported techniques of peripheral nerve blocks including the axillary block for the upper limb and the epidural for the lower limb, while Wan et al. [8] preferred a general anesthesia [8]. However in the Wan study, the neurolyses were performed on both limbs in one time by 2 surgical teams [8]. Pfagraft, long before the rise of neurostimulation, evoked in a letter to the editor the brachial plexus blocks on the patient with leprosy [6]. Thus in this serie based on criteria of conventional neurostimulation decreed by french recommendations for best practise (SFAR), we had slightly raised the stimulation intensity to $3 \mathrm{~mA}$ in order to ensure an optimal nervous excitability. Moreover, it's the amplitude of action potentials rather than the rate of conduction that characterize hansenian neuropathy [9]. All patients had observable and effective motor responses at this intensity, thus modulating the responses around the current threshold. The minimal intensity obtained with neurostimulation was comparable to experimental model [10].

Some patients showed a threshold level greater than $0.6 \mathrm{~mA}$ with block success. We believe that this success of the block, despite the high stimulation intensities, could not be attributed in the absolute to leprous neuropathy. Sauter et al demonstrate an inverse relationship between impedance measurements and current thresholds and suggest that current settings used for nerve stimulation may require adjustment based on the tissue type [11]. The leprous neuropathy is characterized by an inflammatory infiltration of the perinerve which can vary the threshold of excitability, although the influence of nerve composition on electrical nerve stimulation in regional anesthesia has not been well investigated [12]. In this context, ultrasound guidance retains its value by making it possible to specify the actual current threshold. However, its use is limited by its cost and availability in leprosy endemic areas. This study show also no significant onset time between leprous compared to general population. However, our data remains difficult to interpret because all the tests were carried out at 15 minutes after the puncture, but also the use of 2 different types of local anesthetic namely bupivacaine $0.5 \%$ and ropivacaine $0.75 \%$.

The average duration of the sensory blocks in our study was similar to the one in the literature for non leprous patients [13].
Six patients presented prolonged blocks to $24 \mathrm{~h}$ and $26 \mathrm{~h}$ with ad integrum return, without being significant in this cohort. Therefore this study provides likely data showing a prolonged effect of local anesthetics in leprous. However, further comparatives studies to non leprous patient are needed to confirm. These types of studies have been performed on patients with diabetes and have demonstrated a delay in recovery of the block with a longacting local anesthetic [14]. However leprous neuropathy is different from the diabetic one, and in no way could the data from these clinical and animal studies be extrapolated to the leprosy subject. The main mechanism of clinical nerve injury found, is hyperglycaemia toxicity $[15,16]$. We decided to include leprous patient using monofilament test to evaluate the neuropathy. First this method allowed to exclude patient who where not able to perform the neuroclinic test. Secondly in electrodiagnostic studies, lef calibrated filament at $0,2 \mathrm{~g}$ has been described as the most sensitive and specific test for the clinical evaluation of leprous patient [17]. Although, most of leprous patients had normal clinical sensory assessment.

Some limitations in our retropective study should be considered. First, we did not perform an electrodiagnostic evaluation in all our patients, which is considered as the reference method for the assessment of neuropathy. However, in the present study the number of nerve blocked is likely enough to inforce the useful nerve block by neurostimulation.

On the whole population, $86 \%$ were reevaluated without any complication that can be attached to the nerve stimulated guided blocks. This study also confirms the scarcity of nerve complications secondary to locoregional anesthesia $[18,19]$. The application of our results to patient suffering from clinical nerve injury finds all its interest in our developing countries where the lack of resources is common and also where regional anesthesia is low cost. However we believe that the contribution of ultrasound guided in performing these blocks will increase the fiability with much more security.

\section{Conclusion}

Leprosy continues to be rampant in developing countries then patients often need limb surgery due to functional nerve disabilities. Our retrospective study that investigated the practise of nerve stimulated guided peripheral nerve blocks demonstrate the utility of these techniques on providing good anesthesia and analgesia in condition of low resources. Therefore, we find that ultrasound guided associated with nerve stimulator will enhance the security in performing those nerve blocks in leprous with multi-neuropathies.

\section{Declaration of Interest}

None declared.

\section{Referencces}

1. World Health Organization Prevalence of leprosy.

2. World Health Organization (2015) Weekly Epidemiological Record. 90: 471-76 
3. Sharma P, Kar HK, Beena KR, Kaur H, Narayan R (1996) Disabilities in multibacillary leprosy patients: before, during and after multidrug therapy. Indian J Lepr 68(2): 127-136.

4. Van Brakel WH, Khawas IB (1994) Nerve damage in leprosy: an epidemiological and clinical study of 396 patients in west Nepal. Part 1. Definitions, methods and frequencies. Lepr Rev 65(3): 204-221.

5. Peripheral nerve block of limbs in the adult (2003) Ann Fr Anesth Reanim 22(6): 567-581.

6. Pfaltzgraff R (1982) Brachial plexus block for upper limb surgery in leprosy. Lepr Rev 53(2): 149-150.

7. Debray M, Hanslik T, Avansi MA, Pabion B, Lortholary O. (2001) Surgical decompression treatment of leprous neuritis at the BomPastor Hospital (Brazilian Amazonia). Rev Med Interne 22(12): 11881195.

8. Wan EL, Rivadeneira AF, Jouvin RM, Dellon AL (2016) Treatment of Peripheral Neuropathy in Leprosy: The Case for Nerve Decompression. Plast Reconstr Surg Glob Open 4(3): 637.

9. Tzourio C, Said G, Millan J (1992). Asymptomatic nerve hypertrophy in lepromatous leprosy: a clinical. Electrophysiological and morphological study. J Neurol 239(7): 367-374.

10. Steinfeldt T, Graf J, Vassiliou T, Morin A, Feldmann K, et al. (2009) High or low current threshold for nerve stimulation for regional anesthesia. Acta Anesthesiol Scand 53(10): 1275-1281.

11. Sauter AR, Dodgson MS, Kalvoy H, Grimnes S, Stubhaug A, Klaastad O (2009) Current threshold for nerve stimulation depends on electrical impedance of the tissue: a study of ultrasound-guided electrical nerve stimulation of the median nerve. Anesth Analg 108(4): 1338-1343.
12. Suleiman M, Hammerman H, Boulos M, Kapeliovich MR, Suleiman A, et al. (2005) Fasting glucose is an important independent risk factor for 30-day mortality in patients with acute myocardial infarction: a prospective study. Circulation 111(6): 754 -760.

13. Lui SS, Ngeow J, John RS (2010) Evidence basis for ultrasound-guided block characteristics: onset, quality, and duration. Reg Anesth Pain Med 35(2): S26-S35.

14. Cuvillon P, Reubrecht V, Zoric L, Lemoine L, Belin M, et al. (2013) Comparison of subgluteal sciatic nerve block duration in type 2 diabetic and non-diabetic patients. Br J Anaesth 110(5): 823-30.

15. Olmos PR, Cataland S, O’Dorisio TM, Casey CA, Smead WL, et al. (1995) The Semmes-Weinstein monofilament as a potential predictor of foot ulceration in patients with noninsulin- dependent diabetes. Am J Med Sci 309(2): 76-82.

16. Kanji JN, Anglin RE, Hunt DL, Panju A (2010) Does this patient with dia- betes have large-fiber peripheral neuropathy? J Am Med Assoc 303(15): $1526-1532$.

17. Grimaud J, Verchot B, Chapuis F, Discamps G, Vallat JM, et al. (2001) Détection de la neuropathie hansénienne au Sénégal. Rev Neurol (Paris) 3 (Suppl).

18. Brull R, Hadzic A, Reina MA, Barrington MJ (2015) Physiopathology and etiology of nerve injury following peripheral nerve blockade. Reg Anesth Pain Med 40(5): 479-490.

19. Brull R, Mc Cartney CJL, Chan VWS, El Beheiry H (2007) Neurological complications after regional anesthesia : contemporary estimates of the risk. Anesth Analg 104(4): 965-974.

Your next submission with Juniper Publishers
will reach you the below assets
- Quality Editorial service
- Swift Peer Review
- Reprints availability
- E-prints Service
- Manuscript Podcast for convenient understanding
- Global attainment for your research
- Manuscript accessibility in different formats
( Pdf, E-pub, Full Text, Audio)
- Unceasing customer service
Track the below URL for one-step submission
https://juniperpublishers.com/online-submission.php

